\title{
Trends in household expenditure over time
}

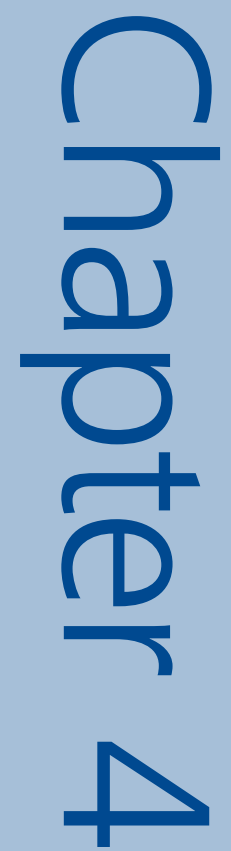




\section{Trends in household expenditure over time}

This chapter presents household expenditure data over time using both the Family Expenditure Survey (FES) and the Classification of Individual COnsumption by Purpose (COICOP) classifications. COICOP is the internationally agreed standard classification for reporting household consumption expenditure.

Prior to the introduction of the EFS in 2001-02, expenditure data were collected via the Family Expenditure Survey (FES) and were classified using a different system, the FES classification. Time series data based on the FES classification are presented in Tables 4.1 and 4.2. These data have been retained and published alongside the COICOP time series, as they illustrate family spending patterns since 1990, whereas COICOP data are only available from 2001-02. The COICOP data are presented in Tables 4.3 and 4.4.

It should be noted that time series data based on the FES classification from 2001-02 (Tables 4.1 and 4.2) have been constructed by mapping EFS COICOP data onto the FES classification. This has been done to preserve a time series from 1990 to 2007. These data are presented solely for the purpose of historical comparisons. In addition, from 2001-02, the 'all expenditure groups' totals in Table 4.1 may not equal the sum of the component commodities or services, as the mapping process is not exact. It should also be stressed that it is not possible to directly compare the FES time series data with the COICOP data presented in this chapter and the other chapters and appendices in the publication. This is due to the differences in the definitions of the classification headings (for example, 'Motoring' in the FES classification includes vehicle insurance, whereas the 'Transport' heading under COICOP excludes this expenditure item).

COICOP time series data in this publication are not directly comparable with UK National Accounts household expenditure data, which are published in Consumer Trends (www.statistics. gov.uk/statbase/Product.asp?vlnk=242). The Family Spending time series tables present average weekly household expenditure at 2007 prices. In contrast, Consumer Trends tables present total household final consumption expenditure at current prices and also as chained volume measures. National Accounts figures draw on a number of sources in addition to the EFS (please refer to Appendix B of Consumer Trends for details) and may be more appropriate for deriving long-term trends on expenditure. 


\section{Table 4.1}

\section{Household expenditure based on the FES classification, 1990 to 2007 at 2007 prices $^{1}$}

\begin{tabular}{|c|c|c|c|c|c|c|c|c|c|}
\hline & 1990 & 1992 & $\begin{array}{r}1994 \\
-95\end{array}$ & $\begin{array}{r}1995^{2} \\
-96\end{array}$ & $\begin{array}{r}1995^{3} \\
-96\end{array}$ & $\begin{array}{r}1996 \\
-97\end{array}$ & $\begin{array}{r}1997 \\
-98\end{array}$ & $\begin{array}{r}1998 \\
-1999\end{array}$ & $\begin{array}{r}1999 \\
-2000\end{array}$ \\
\hline Weighted number of households (thousands) & & & & & 24,130 & 24,310 & 24,560 & 24,660 & 25,330 \\
\hline Total number of households in sample & 7,050 & 7,420 & 6,850 & 6,800 & 6,800 & 6,420 & 6,410 & 6,630 & 7,100 \\
\hline Total number of persons & 17,440 & 18,170 & 16,620 & 16,590 & 16,590 & 15,730 & 15,430 & 16,220 & 16,790 \\
\hline Average number of persons per household & 2.5 & 2.5 & 2.4 & 2.4 & 2.4 & 2.5 & 2.4 & 2.4 & 2.3 \\
\hline
\end{tabular}

Commodity or service

Average weekly household expenditure ( $f$ )

\begin{tabular}{|c|c|c|c|c|c|c|c|c|c|c|}
\hline 1 & Housing (Net) ${ }^{7}$ & 72.80 & 70.60 & 66.00 & 66.40 & 67.00 & 65.80 & 66.90 & 72.10 & 70.80 \\
\hline 2 & Fuel and power & 18.20 & 19.40 & 18.40 & 17.80 & 17.70 & 17.80 & 16.30 & 14.70 & 14.10 \\
\hline 3 & Food and non-alcoholic drinks & 73.40 & 71.10 & 71.70 & 72.80 & 74.40 & 75.40 & 74.30 & 74.30 & 74.00 \\
\hline 4 & Alcoholic drink & 16.40 & 16.50 & 17.50 & 15.70 & 16.90 & 17.60 & 18.40 & 17.60 & 19.00 \\
\hline 5 & Tobacco & 7.90 & 8.00 & 8.00 & 8.00 & 8.10 & 8.30 & 8.20 & 7.30 & 7.40 \\
\hline 6 & Clothing and footwear & 26.30 & 24.40 & 24.30 & 23.60 & 24.50 & 25.20 & 26.40 & 27.40 & 26.00 \\
\hline 7 & Household goods & 32.80 & 32.70 & 32.20 & 32.30 & 32.80 & 35.80 & 35.10 & 37.40 & 38.20 \\
\hline 8 & Household services & 20.10 & 20.00 & 21.40 & 20.80 & 20.90 & 21.70 & 23.00 & 23.90 & 23.50 \\
\hline 9 & Personal goods and services & 15.50 & 15.20 & 15.30 & 15.90 & 16.20 & 15.90 & 16.50 & 16.80 & 17.20 \\
\hline 10 & Motoring & 55.40 & 53.20 & 51.40 & 50.90 & 52.60 & 56.60 & 61.50 & 65.30 & 65.30 \\
\hline 11 & Fares and other travel costs & 10.10 & 10.70 & 9.40 & 8.50 & 9.10 & 10.40 & 11.20 & 10.50 & 11.40 \\
\hline 12 & Leisure goods & 18.50 & 19.90 & 19.70 & 18.90 & 19.90 & 21.20 & 22.60 & 22.50 & 23.00 \\
\hline 13 & Leisure services & 35.30 & 41.10 & 44.30 & 44.10 & 45.10 & 47.00 & 51.40 & 52.90 & 54.60 \\
\hline 14 & Miscellaneous & 2.20 & 2.60 & 3.30 & 3.30 & 1.70 & 1.40 & 1.40 & 1.50 & 1.80 \\
\hline 1-14 & All expenditure groups & 404.90 & 405.50 & 403.10 & 399.00 & 406.70 & 420.20 & 433.20 & 444.40 & 446.40 \\
\hline \multicolumn{11}{|c|}{ Average weekly expenditure per person (f) } \\
\hline \multirow{2}{*}{\multicolumn{2}{|c|}{ Total expenditure }} & 162.00 & 162.20 & 167.90 & 166.20 & 170.00 & 168.10 & 180.50 & 185.20 & 194.10 \\
\hline & & & \multicolumn{8}{|c|}{ Average weekly household expenditure $(f)^{8}$} \\
\hline \multicolumn{2}{|c|}{ Gross income (f) } & 520 & 512 & 525 & 524 & 536 & 543 & 558 & 577 & 596 \\
\hline \multicolumn{2}{|c|}{ Disposable income (f) } & 422 & 418 & 424 & 422 & 431 & 444 & 455 & 468 & 486 \\
\hline
\end{tabular}

Note: The commodity and service categories are not comparable to the COICOP categories used in Tables 4.3 and 4.4.

Figures are based on FES data between 1984 and 2000-01 and EFS data thereafter.

1 Figures have been deflated to 2007 prices using the RPI all items index.

2 From 1984 to this version of 1995-96, figures shown are based on unweighted, adult only data.

3 From this version of 1995-96, figures are shown based on weighted data, including children's expenditure. Weighting is based on the population figures from the 1991 and 2001 Censuses

4 From 2001-02 onwards, commodities and services are based on COICOP codes broadly mapped to FES.

5 From 1995-96 to this version of 2006, figures shown are based on weighted data using non-response weights based on the 1991 Census and population figures from the 1991 and 2001 Censuses

6 From this version of 2006, figures shown are based on weighted data using updated weights, with non-response weights and population figures based on the 2001 Census

7 An improvement to the imputation of mortgage interest payments has been implemented for 2006 and 2007 data which should lead to more accurate figures. This will lead to a slight discontinuity. An error was discovered in the derivation of mortgage capital repayments which was leading to double counting. This has been amended for the 2006 and 2007 data.

8 Does not include imputed income from owner-occupied and rent-free households. 
Table 4.1

\section{Household expenditure based on the FES classification, 1990 to 2007} at 2007 prices $^{1}$ (cont.)

\begin{tabular}{|c|c|c|c|c|c|c|c|c|c|c|}
\hline \multicolumn{2}{|r|}{ 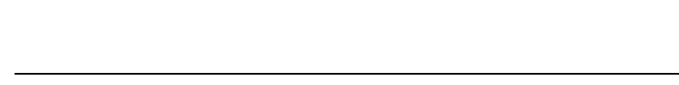 } & $\begin{array}{r}2000 \\
-01\end{array}$ & $\begin{array}{r}2001^{4} \\
-02\end{array}$ & $\begin{array}{r}2002 \\
-03\end{array}$ & $\begin{array}{r}2003 \\
-04\end{array}$ & $\begin{array}{r}2004 \\
-05\end{array}$ & $\begin{array}{r}2005 \\
-06\end{array}$ & $2006^{5}$ & $2006^{6}$ & 2007 \\
\hline \multicolumn{2}{|r|}{ Weighted number of households (thousands) } & 25,030 & 24,450 & 24,350 & 24,670 & 24,430 & 24,800 & 24,790 & 25,440 & 25,350 \\
\hline \multicolumn{2}{|r|}{ Total number of households in sample } & 6,640 & 7,470 & 6,930 & 7,050 & 6,800 & 6,790 & 6,650 & 6,650 & 6,140 \\
\hline \multicolumn{2}{|r|}{ Total number of persons } & 15,930 & 18,120 & 16,590 & 16,970 & 16,260 & 16,090 & 15,850 & 15,850 & 14,650 \\
\hline \multicolumn{2}{|r|}{ Weighted average number of persons per household } & 2.4 & 2.4 & 2.4 & 2.4 & 2.4 & 2.4 & 2.4 & 2.3 & 2.4 \\
\hline \multicolumn{3}{|c|}{ Commodity or service } & \multicolumn{6}{|c|}{ Average weekly household expenditure (f) } & & \\
\hline 1 & Housing (Net) ${ }^{7}$ & 77.10 & 78.30 & 77.60 & 79.10 & 84.30 & 86.50 & 87.00 & 86.80 & 92.00 \\
\hline 2 & Fuel and power & 14.30 & 13.90 & 13.60 & 13.60 & 13.80 & 14.80 & 16.60 & 16.40 & 17.20 \\
\hline 3 & Food and non-alcoholic drinks & 74.70 & 73.50 & 74.90 & 73.50 & 73.90 & 72.70 & 73.40 & 72.60 & 71.40 \\
\hline 4 & Alcoholic drink & 18.10 & 17.00 & 17.30 & 16.70 & 16.30 & 15.80 & 15.50 & 15.40 & 14.70 \\
\hline 5 & Tobacco & 7.30 & 6.50 & 6.30 & 6.20 & 5.50 & 4.90 & 4.80 & 4.90 & 4.60 \\
\hline 6 & Clothing and footwear & 26.50 & 26.50 & 25.60 & 25.40 & 25.80 & 24.00 & 23.90 & 23.60 & 21.60 \\
\hline 8 & Household services & 26.50 & 28.00 & 27.20 & 28.20 & 28.90 & 29.00 & 27.70 & 27.50 & 26.50 \\
\hline 9 & Personal goods and services & 17.70 & 17.80 & 17.70 & 18.30 & 17.60 & 18.10 & 18.40 & 18.30 & 17.80 \\
\hline 10 & Motoring & 66.40 & 68.80 & 71.80 & 70.60 & 68.70 & 68.30 & 65.10 & 63.70 & 62.00 \\
\hline 11 & Fares and other travel costs & 11.40 & 11.10 & 11.30 & 10.90 & 10.40 & 11.80 & 11.60 & 11.50 & 10.90 \\
\hline 12 & Leisure goods & 23.80 & 23.30 & 23.80 & 24.20 & 23.50 & 20.80 & 20.50 & 20.20 & 20.10 \\
\hline 13 & Leisure services & 61.00 & 61.70 & 62.40 & 62.30 & 65.40 & 67.40 & 69.20 & 68.10 & 61.70 \\
\hline 14 & Miscellaneous & 0.90 & 2.20 & 2.30 & 2.20 & 2.20 & 2.30 & 2.20 & 2.20 & 1.90 \\
\hline \multicolumn{2}{|c|}{ 1-14 All expenditure groups } & 465.10 & 468.00 & 471.10 & 470.90 & 475.40 & 472.30 & 471.70 & 466.60 & 456.80 \\
\hline \multirow{2}{*}{\multicolumn{2}{|c|}{$\begin{array}{l}\text { Average weekly expenditure per person (f) } \\
\text { Total expenditure }\end{array}$}} & & & & & & & & & \\
\hline & & 197.60 & 197.80 & 197.80 & 199.80 & 199.20 & 199.20 & 199.50 & 199.60 & 193.80 \\
\hline \multicolumn{2}{|c|}{ Gross income (f) } & 606 & 642 & 643 & 646 & 660 & 659 & 669 & 662 & 659 \\
\hline \multicolumn{2}{|c|}{ Disposable income (f) } & 493 & 525 & 528 & 525 & 537 & 535 & 543 & 537 & 534 \\
\hline
\end{tabular}

Note: The commodity and service categories are not comparable to the COICOP categories used in Tables 4.3 and 4.4

Figures are based on FES data between 1984 and 2000-01 and EFS data thereafter.

1 Figures have been deflated to 2007 prices using the RPI all items index.

2 From 1984 to this version of 1995-96, figures shown are based on unweighted, adult only data.

3 From this version of 1995-96, figures are shown based on weighted data, including children's expenditure. Weighting is based on the population figures from the 1991 and 2001 Censuses

4 From 2001-02 onwards, commodities and services are based on COICOP codes broadly mapped to FES.

5 From 1995-96 to this version of 2006, figures shown are based on weighted data using non-response weights based on the 1991 Census and population figures from the 1991 and 2001 Censuses

6 From this version of 2006, figures shown are based on weighted data using updated weights, with non-response weights and population figures based on the 2001 Census

7 An improvement to the imputation of mortgage interest payments has been implemented for 2006 and 2007 data which should lead to more accurate figures. This will lead to a slight discontinuity. An error was discovered in the derivation of mortgage capital repayments which was leading to double counting. This has been amended for the 2006 and 2007 data.

8 Does not include imputed income from owner-occupied and rent-free households. 


\section{Table 4.2}

\section{Household expenditure as a percentage of total expenditure, 1990 to 2007 based on the FES classification at 2007 prices $^{1}$}

\begin{tabular}{|c|c|c|c|c|c|c|c|c|c|}
\hline & 1990 & 1992 & $\begin{array}{r}1994 \\
-95\end{array}$ & $\begin{array}{r}1995^{2} \\
-96\end{array}$ & $\begin{array}{r}1995^{3} \\
-96\end{array}$ & $\begin{array}{r}1996 \\
-97\end{array}$ & $\begin{array}{r}1997 \\
-98\end{array}$ & $\begin{array}{r}1998 \\
-99\end{array}$ & $\begin{array}{r}1999 \\
-2000\end{array}$ \\
\hline Weighted number of households (thousands) & & & & & 24,130 & 24,310 & 24,560 & 24,660 & 25,330 \\
\hline Total number of households in sample & 7,050 & 7,420 & 6,850 & 6,800 & 6,800 & 6,420 & 6,410 & 6,630 & 7,100 \\
\hline Total number of persons & 17,440 & 18,170 & 16,620 & 16,590 & 16,590 & 15,730 & 15,430 & 16,220 & 16,790 \\
\hline Average number of persons per household & 2.5 & 2.5 & 2.4 & 2.4 & 2.4 & 2.5 & 2.4 & 2.4 & 2.3 \\
\hline
\end{tabular}

Commodity or service

Percentage of total expenditure

\begin{tabular}{|c|c|c|c|c|c|c|c|c|c|c|}
\hline 1 & Housing (Net) ${ }^{7}$ & 18 & 17 & 16 & 17 & 16 & 16 & 15 & 16 & 16 \\
\hline 2 & Fuel and power & 4 & 5 & 5 & 4 & 4 & 4 & 4 & 3 & 3 \\
\hline 3 & Food and non-alcoholic drinks & 18 & 18 & 18 & 18 & 18 & 18 & 17 & 17 & 17 \\
\hline 5 & Tobacco & 2 & 2 & 2 & 2 & 2 & 2 & 2 & 2 & 2 \\
\hline 6 & Clothing and footwear & 6 & 6 & 6 & 6 & 6 & 6 & 6 & 6 & 6 \\
\hline 8 & Household services & 5 & 5 & 5 & 5 & 5 & 5 & 5 & 5 & 5 \\
\hline 9 & Personal goods and services & 4 & 4 & 4 & 4 & 4 & 4 & 4 & 4 & 4 \\
\hline 10 & Motoring & 14 & 13 & 13 & 13 & 13 & 13 & 14 & 15 & 15 \\
\hline 11 & Fares and other travel costs & 3 & 3 & 2 & 2 & 2 & 2 & 3 & 2 & 3 \\
\hline 12 & Leisure goods & 5 & 5 & 5 & 5 & 5 & 5 & 5 & 5 & 5 \\
\hline 13 & Leisure services & 9 & 10 & 11 & 11 & 11 & 11 & 12 & 12 & 12 \\
\hline $1-14$ & All expenditure groups & 100 & 100 & 100 & 100 & 100 & 100 & 100 & 100 & 100 \\
\hline
\end{tabular}

1 Figures have been deflated to 2007 prices using the RPI all items index.

2 From 1984 to this version of 1995-96, figures shown are based on unweighted, adult only data.

3 From this version of 1995-96, figures are shown based on weighted data, including children's expenditure. Weighting is based on the population figures from the 1991 and 2001 Censuses

4 From 2001-02 onwards, commodities and services are based on COICOP codes broadly mapped to FES.

5 From 1995-96 to this version of 2006, figures shown are based on weighted data using non-response weights based on the 1991 Census and population figures from the 1991 and 2001 Censuses

6 From this version of 2006, figures shown are based on weighted data using updated weights, with non-response weights and population figures based on the 2001 Census

7 An improvement to the imputation of mortgage interest payments has been implemented for 2006 and 2007 data which should lead to more accurate figures. This will lead to a slight discontinuity. An error was discovered in the derivation of mortgage capital repayments which was leading to double counting. This has been amended for the 2006 and 2007 data. 
Table 4.2

Household expenditure as a percentage of total expenditure, 1990 to 2007 based on the FES classification at 2007 prices $^{1}$ (cont.)

\begin{tabular}{|c|c|c|c|c|c|c|c|c|c|c|}
\hline & & $\begin{array}{r}2000 \\
-01\end{array}$ & $\begin{array}{r}2001^{4} \\
-02\end{array}$ & $\begin{array}{r}2002 \\
-03\end{array}$ & $\begin{array}{r}2003 \\
-04\end{array}$ & $\begin{array}{r}2004 \\
-05\end{array}$ & $\begin{array}{r}2005 \\
-06\end{array}$ & $2006^{5}$ & $2006^{6}$ & 2007 \\
\hline \multicolumn{2}{|r|}{ Weighted number of households (thousands) } & 25,030 & 24,450 & 24,350 & 24,670 & 24,430 & 24,800 & 24,790 & 25,440 & 25,350 \\
\hline \multicolumn{2}{|r|}{ Total number of households in sample } & 6,640 & 7,470 & 6,930 & 7,050 & 6,800 & 6,790 & 6,650 & 6,650 & 6,140 \\
\hline \multicolumn{2}{|r|}{ Total number of persons } & 15,930 & 18,120 & 16,590 & 16,970 & 16,260 & 16,090 & 15,850 & 15,850 & 14,650 \\
\hline \multicolumn{2}{|r|}{ Weighted average number of persons per household } & 2.4 & 2.4 & 2.4 & 2.4 & 2.4 & 2.4 & 2.4 & 2.3 & 2.4 \\
\hline \multicolumn{3}{|c|}{ Commodity or service } & \multicolumn{6}{|c|}{ Percentage of total expenditure } & & \\
\hline 1 & Housing (Net) $)^{7}$ & 17 & 17 & 16 & 17 & 18 & 18 & 18 & 19 & 20 \\
\hline 2 & Fuel and power & 3 & 3 & 3 & 3 & 3 & 3 & 4 & 4 & 4 \\
\hline 3 & Food and non-alcoholic drinks & 16 & 16 & 16 & 16 & 16 & 15 & 16 & 16 & 16 \\
\hline 4 & Alcoholic drink & 4 & 4 & 4 & 4 & 3 & 3 & 3 & 3 & 3 \\
\hline 5 & Tobacco & 2 & 1 & 1 & 1 & 1 & 1 & 1 & 1 & 1 \\
\hline 6 & Clothing and footwear & 6 & 6 & 5 & 5 & 5 & 5 & 5 & 5 & 5 \\
\hline 8 & Household services & 6 & 6 & 6 & 6 & 6 & 6 & 6 & 6 & 6 \\
\hline 9 & Personal goods and services & 4 & 4 & 4 & 4 & 4 & 4 & 4 & 4 & 4 \\
\hline 10 & Motoring & 14 & 15 & 15 & 15 & 14 & 14 & 14 & 14 & 14 \\
\hline 11 & Fares and other travel costs & 2 & 2 & 2 & 2 & 2 & 3 & 2 & 2 & 2 \\
\hline 12 & Leisure goods & 5 & 5 & 5 & 5 & 5 & 4 & 4 & 4 & 4 \\
\hline 13 & Leisure services & 13 & 13 & 13 & 13 & 14 & 14 & 15 & 15 & 13 \\
\hline 14 & Miscellaneous & 0 & 0 & 0 & 0 & 0 & 0 & 0 & 0 & 0 \\
\hline $1-14$ & All expenditure groups & 100 & 100 & 100 & 100 & 100 & 100 & 100 & 100 & 100 \\
\hline
\end{tabular}

1 Figures have been deflated to 2007 prices using the RPI all items index.

2 From 1984 to this version of 1995-96, figures shown are based on unweighted, adult only data.

3 From this version of 1995-96, figures are shown based on weighted data, including children's expenditure. Weighting is based on the population figures from the 1991 and 2001 Censuses

4 From 2001-02 onwards, commodities and services are based on COICOP codes broadly mapped to FES.

5 From 1995-96 to this version of 2006, figures shown are based on weighted data using non-response weights based on the 1991 Census and population figures from the 1991 and 2001 Censuses

6 From this version of 2006, figures shown are based on weighted data using updated weights, with non-response weights and population figures based on the 2001 Census

7 An improvement to the imputation of mortgage interest payments has been implemented for 2006 and 2007 data which should lead to more accurate figures. This will lead to a slight discontinuity. An error was discovered in the derivation of mortgage capital repayments which was leading to double counting. This has been amended for the 2006 and 2007 data. 


\section{Table 4.3}

Household expenditure based on COICOP classification, 2001-02 to 2007 at 2007 prices ${ }^{1}$ based on weighted data and including children's expenditure

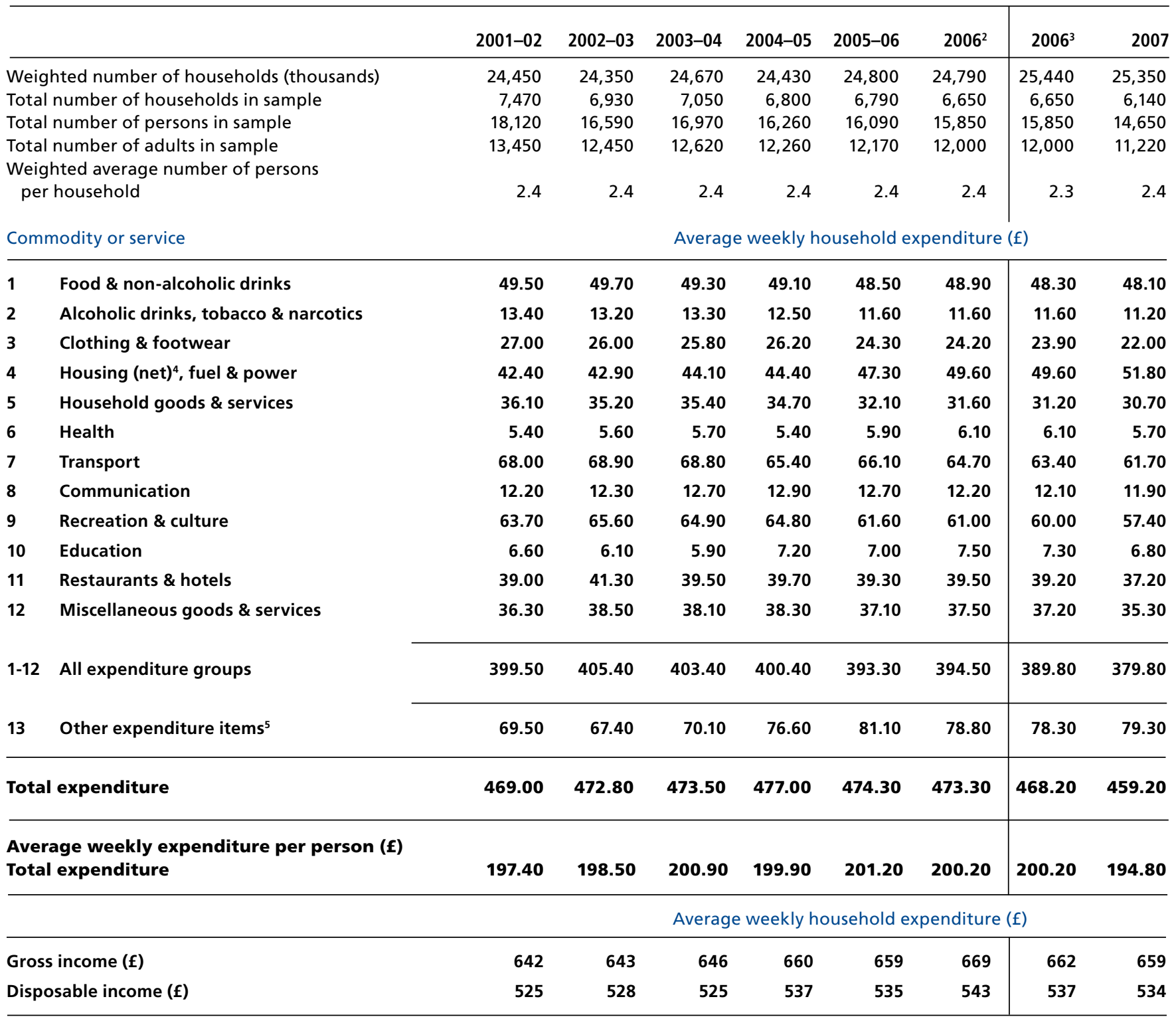

Note: The commodity and service categories are not comparable to the FES categories used in Tables 4.2 and 4.3.

1 Figures have been deflated to 2007 prices using the RPI all items index.

2 From 1998-99 to this version of 2006, figures shown are based on weighted data using non-response weights based on the 1991 Census and population figures from the 1991 and 2001 Censuses

3 From this version of 2006, figures shown are based on weighted data using updated weights, with non-response weights and population figures based on the 2001 Census

4 Excluding mortgage interest payments, council tax and Northern Ireland rates

5 An improvement to the imputation of mortgage interest payments has been implemented for 2006 and 2007 data which should lead to more accurate figures. This will lead to a slight discontinuity. 


\section{Table 4.4}

\section{Household expenditure as a percentage of total expenditure based on COICOP classification, 2001-02 to 2007 at 2007 prices $^{1}$}

based on weighted data and including children's expenditure

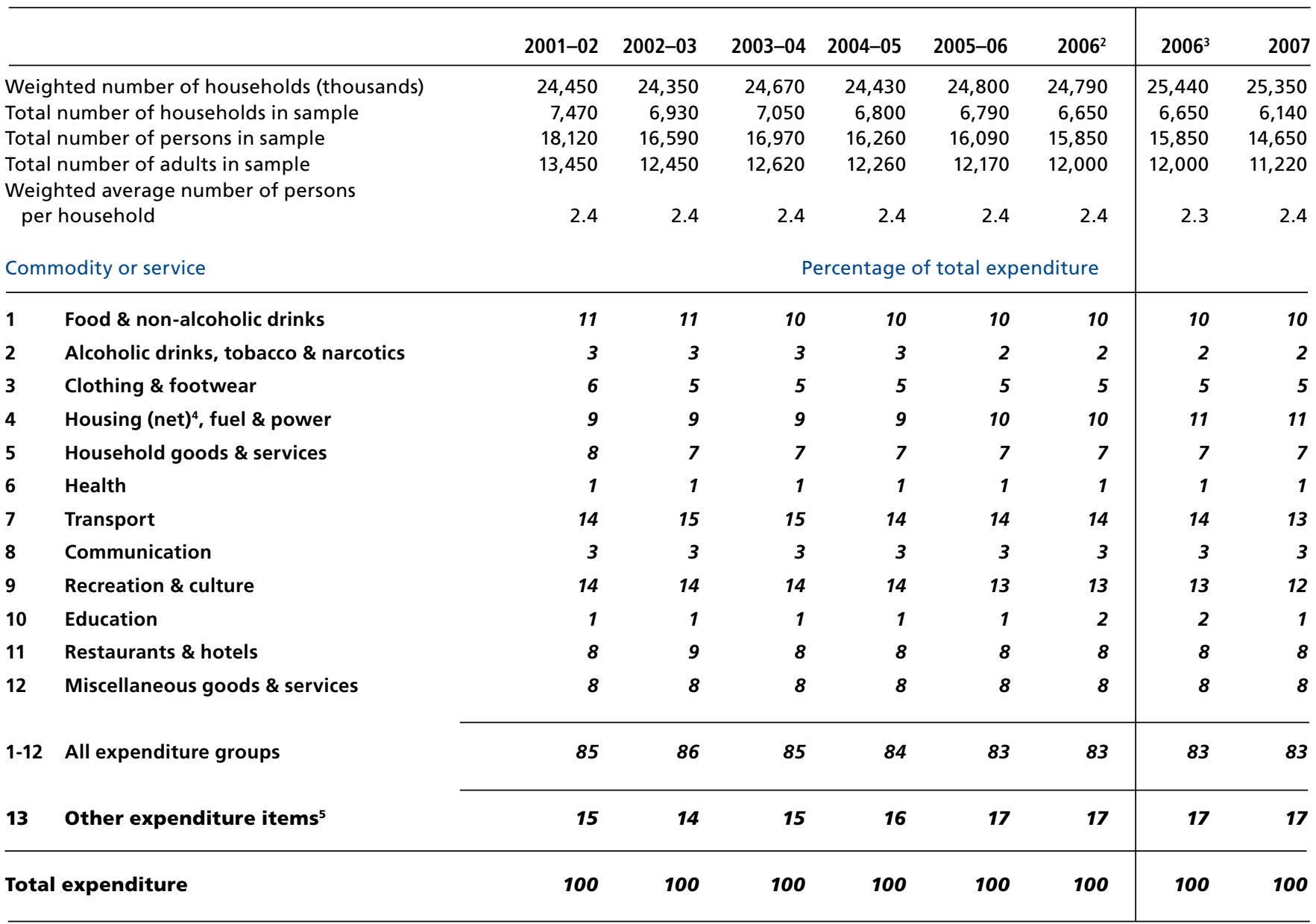

Note: The commodity and service categories are not comparable to the FES categories used in Tables 4.2 and 4.3.

1 Figures have been deflated to 2007 prices using the RPI all items index

2 From 1995-96 to this version of 2006, figures shown are based on weighted data using non-response weights based on the 1991 Census and population figures from the 1991 and 2001 Censuses

3 From this version of 2006, figures shown are based on weighted data using updated weights, with non-response weights and population figures based on the 2001 Census

4 Excluding mortgage interest payments, council tax and Northern Ireland rates

5 An improvement to the imputation of mortgage interest payments has been implemented for 2006 and 2007 data which should lead to more accurate figures. This will lead to a slight discontinuity. 